\title{
The link between violence and suicidal behavior among female university students in Spain
}

\section{David Martín-Baena, Olga Mayoral, Marta Talavera \& Isabel Montero}

To cite this article: David Martín-Baena, Olga Mayoral, Marta Talavera \& Isabel Montero (2018):

The link between violence and suicidal behavior among female university students in Spain, Journal of School Violence, DOI: 10.1080/15388220.2018.1453823

To link to this article: https://doi.org/10.1080/15388220.2018.1453823

\section{Published online: 05 Apr 2018.}

Submit your article to this journal

山 Article views: 29

Q View related articles $ऍ$

View Crossmark data $\nearrow$ 


\title{
The link between violence and suicidal behavior among female university students in Spain
}

\author{
David Martín-Baena ${ }^{b}$, Olga Mayoral ${ }^{a}$, Marta Talavera $\mathbb{B}^{\mathrm{a}}$, and Isabel Montero ${ }^{c}$ \\ aDepartment of Didactics of Experimental and Social Sciences, University of Valencia, Valencia, Spain; ${ }^{\text {bDepartment }}$ \\ of Didactics of Experimental and Social Sciences, CIBER de Epidemiologia y Salud Publica (CIBERESP), Madrid, Spain; \\ 'Departament of Medicine, University of Valencia, Valencia, Spain
}

\begin{abstract}
Objective: To explore the association between violence and suicidal behavior in female university students. Method: A convenience sample of 540 female students enrolled in the Nursing and Teacher Training Faculties at the University of Valencia was selected. Violence by partners, nonpartners, and both was compared with suicidal thoughts and suicide attempts. An adjusted logistic regression and the Wald Test were performed to explore whether the effect on student's suicidal behavior differed if a partner or others committed violence. Results: $18.1 \%$ reported suicidal thoughts in the last month and $2.4 \%$ had attempted suicide in the past five years. Suicidal behavior was significantly higher in abused than in nonabused students, although the magnitude was higher when committed by a nonpartner. Conclusions: All forms of violence are strongly associated with suicidal behavior. Understanding the relationship between violence and suicidal thoughts and attempts is a priority for reducing suicide behavior in young women.
\end{abstract}

\section{ARTICLE HISTORY}

Received 17 July 2017

Revised 1 February 2018

Accepted 10 February 2018

\section{KEYWORDS}

Suicidal thoughts; suicide attempts; violence; women; university students

\section{Introduction}

The most consistent findings in research about suicide show that women make more suicide attempts than men, but men are more likely to die in their attempts than women (Hawton, 2000); except in India, were women suicides exceeded men suicides, and rates peak at ages 15-29 and fall in older women (Patel et al., 2012). One possible explanation is based on the differences in the propensity to use lethal means and the different use of substances within the context of suicides (Callanan \& Davis, 2012; Mergl et al., 2015). However, within the same method, suicide attempts have been found to be more lethal in males than in females (Cibis et al., 2012). Life events seem to exert an important influence as a trigger for a suicidal process, beginning with the suicidal ideation, followed by the development of plans and ending with the attempt of suicide, where duration of the suicidal process in much longer in women than in men (Schrijvers, Bollen, \& Sabbe, 2012). The fact that men and women differ in their roles, responsibilities, status and power and the socially constructed differences interaction with biological differences, may contribute to the differences in mental health and suicidal behavior (Wunderlich, Bronisch, Wittchen, \& Carter, 2001).

Women suicides have been found lower in countries that emphasize social equality (WebsterRudmin, Ferrada-Noli, \& Skolbekken, 2003); in the WHO European region male-female suicide rate is 4:1; the highest in the world (Värnik, 2012). Spain has lower suicide rate than other European countries, but the number of suicides increased an 11\% between 2005 and 2013, and one in three suicides were carried out by women ages $15-29$, becoming the first cause on nonnatural death for 
Spanish young women (Spanish Observatory for Suicide, 2013). Although the number of suicide attempts in young people in Europe is more than 20 times higher than estimated of completed suicide (Hawton et al., 1998), it is important to note that most countries collect and report national data on completed suicides and few record data on suicide attempts. Despite recognizing that suicidal behavior is a public health problem and one of the most important contributors to the global burden of morbidity among women (Beautrais, 2006), knowledge about the prevalence and risk factors of suicidal ideation and attempts in young people is still very limited (Nock et al., 2008).

Violence against women has been recognized as a significant contributor to women's mental ill health (Krug, Dahlberg, Mercy, Zwi, \& Lozano, 2002). But the relationship between violence and depression is bidirectional, since women exposed to violence are at higher risk of depression and women with depressive symptoms are more likely to experience violence by a partner (La Flair, Bradshaw, \& Campbell, 2011). A previous systematic review study concluded that the relationship between violence by an intimate partner and suicidal behavior is consistently strong, even with different study designs, samples and measuring both abuse and suicidality (McLaughlin, O'Carroll, \& O'Connor, 2012). However, there are other forms of violence against women with long-term mental health consequences that persist beyond the period of abuse (Montero et al., 2011; Sutherland, Bybee, \& Sullivan, 1998). Even so, the impact of violence by others than the partner on women's mental health has received less attention.

University students differ from undergraduate students and young people in general, as they support social and academic pressures different from the rest of the population (Eisenberg, Gollust, Golberstein, \& Hefner, 2007). To the date, most of the studies focused on adolescents or high school students. Although psychological distress, thoughts and suicide attempts are common among university students (Eskin et al., 2016) and violence has been found to be strongly associated with suicidal behavior in young women (Watts et al., 2011), few studies assessed the association between violence by someone other than a partner and suicidal behavior in female university students. The present study aims to explore the extent of the association between interpersonal violence and suicidal behavior in female university students and to explore whether the effects on suicidal thoughts and suicide attempts differ among female university students abused by a partner or by others than a partner.

\section{Method}

This cross-sectional study used data from a previous Spanish survey that assesses the impact of violence on women university students' health (Martín-Baena, Talavera, \& Montero, 2016). The sample was selected by a convenient approach among female students enrolled in the academic year 2013-2014 at the Nursing and Teacher Training Faculties of the University of Valencia. Of the 540 students approached, two declined to participate and were replaced by two others of the same age and academic group. The study is part of a research project (SMI 23/2014), funded by the Regional Health Department and approved by the Ethic Committee of the University of Valencia.

\section{Survey instrument and measures}

Based on the evidence that diagnosis of suicidal behavioral self-reported interview is consistent with face-to-face interviews (Kessler \& Ustün, 2004), information was collected through a brief structural self-reported questionnaire. It contains questions on suicidal behavior (suicidal thoughts and attempts), lifetime violence, psychological distress and specific socio-demographic characteristics (age, nationality, habitual residence, and social support). After explaining the study purpose and requiring written informed consent, students completed the questionnaire, put it in a sealed envelope and placed it in a box to ensure anonymity.

Suicidal ideation refers to thoughts about engaging in behaviors that are intended to end one's life and suicide attempt is defined as deliberate try to cause harm to oneself with at least some intent to 
die. Suicidal behavior was assessed by the EMA questionnaire validated in a sample of Spanishspeaking students (Espinoza-Gómez et al., 2010), with a Cronbach's alpha of 0.79. The EMA contains four questions of suicidal behavior: three to assess the occurrence of suicidal thoughts in the last month: "Have you seriously considered it is not worth living?"; "Have you come to think that it is better to be dead than alive?"; "Have you wanted to end your life?" and one for suicide attempts: "Over the last five years, have you tried to commit suicide?"

\section{Interpersonal violence}

The term "interpersonal violence against women" involves the infliction or threatened infliction of physical, sexual or psychological violence with the intention of causing harm or exercising power and control over a woman or girl (Krantz \& García-Moreno, 2005). Women were considered victims of interpersonal violence if reported to have been physically (hit, slapped, kicked, pushed), psychologically (threatened, insulted, humiliated, harassed or excessively controlled) or sexually (unwanted or forced sexual experiences) abused, sometimes or many times, in the past or at present. These three questions had shown a high comprehensibility and acceptability when used in a previous study, with a Cronbach's alpha reliability coefficient of 0.82 (Ruiz-Perez et al., 2006). A woman was considered to have experienced abuse if she reported any physical, psychological or sexual abuse across her lifespan perpetrated by a partner (IPV). Given that violence inflicted by a partner and by someone other than a partner (a relative, a friend, a classmate or an unknown person) is not mutually exclusive, students abused by a partner and by others were classified as abused by both. Three independent categories were established: violence committed by an intimate partner (IPV), by other than a partner (non-IPV) and by both (IPV and non-IPV).

\section{Adjusting variables}

As research shows a relationship between suicide and common mental health conditions, psychological distress was considered as potential confounding factor for analysis. It was assessed by the General Health Questionnaire (GHQ-12), used worldwide and for decades in Spain, in order to analyze the mental health impact on women victim of violence (Lagdons, Armour, \& Tringer, 2014). The Spanish brief validated version of the GHQ-12 gets a good external validity and a Cronbach's alpha reliability coefficient of 0.80 (Sánchez-López \& Dresch, 2008). It contains 12 items with four response options for each, giving a continuous score of $0-12$. Scores equal or higher than three were rated positively for psychological distress in the past month (Barrios, Everett, Simon, \& Brener, 2000).

\section{Statistic analysis}

Prevalence of suicidal thoughts and suicide attempts were estimated and socio-demoghagrafic characteristics compared between students who reported suicidal behavior and those who did not. The association between violence committed by the different perpetrators was calculated for suicidal thoughts and suicide attempts. The difference between the observed frequencies of nominal and ordinal variables was assessed with $\chi^{2}$ test for unpaired samples or with Fisher exact test for low rates. To assess the effect of the different categories of violence on suicidal behavior, they were analyzed with binary logistic regression, adjusted for psychological distress and age, and were independently performed for suicidal thoughts and attempts. The level of statistical significance was set at $p<.05$. The explanatory power of the logistic models was calculated by Nagelkerke $R^{2}$ values and the level of statistical significance was set at $p<.05$. Finally, the Wald Test was used to explore whether the magnitude of the effect on suicidal behavior differs among students abused by partners and by nonpartners. 


\section{Results}

Of the 540 female students involved in the study, 111 (20.5\%) reported suicidal behavior: 98 (18.1\%) suicidal thoughts in the last month and $13(2.4 \%)$ suicide attempts in the last five years. Suicidal thoughts are more frequently reported by students ages 18-21, while those over 21 are more likely to report suicide attempts. Psychological distress was found to be significantly higher among students who reported suicidal behavior-particularly higher in students with suicide attempts (92.3\%) - than in those who didn't report suicidal thoughts or suicide attempts (47.8\%). The vast majority of students are Spanish, live in their parent's home, and have someone around able to support them. No significant differences were found between students who reported suicidal behavior and those who didn't (Table 1).

Table 2 shows the relationship between the different violence categories and suicidal thoughts and suicide attempts. Of the 111 participants who reported suicidal thoughts or suicide attempts, the $67.6 \%$ had experienced violence at least once in their lives. Note that $93(17.2 \%)$ of the students

Table 1. Female university students with and without suicidal behavior profile $(N=540)$.

\begin{tabular}{|c|c|c|c|c|c|c|c|}
\hline & \multirow{3}{*}{$\frac{\text { Never } 429(79.5 \%)}{n(\%)}$} & \multicolumn{6}{|c|}{ Ever $111(20.5 \%)$} \\
\hline & & \multicolumn{3}{|c|}{ Suicidal thoughts 98 (18.1\%) } & \multicolumn{3}{|c|}{ Suicide attempts $13(2.4 \%)$} \\
\hline & & $n(\%)$ & $x^{2}$ & $p$-value & $n(\%)$ & $x^{2}$ & $p$-value* \\
\hline Age & & & 0.77 & .37 & & 1.24 & .26 \\
\hline $18-21$ & $316(73.6)$ & $77(78.6)$ & & & $6(46.2)$ & & \\
\hline $22-25$ & $113(26.4)$ & $21(21.4)$ & & & $7(53.8)$ & & \\
\hline Nationality & & & 1.27 & .25 & & 0.62 & .76 \\
\hline Spanish & $406(94.6)$ & $90(91.8)$ & & & $12(92.3)$ & & \\
\hline Other & $23(5.4)$ & $8(8.2)$ & & & $1(7.7)$ & & \\
\hline Habitual residence & & & 1.20 & .54 & & 1.99 & .24 \\
\hline Parent's home & $351(81.8)$ & $75(77.3)$ & & & $12(92.3)$ & & \\
\hline Student's residence or shared apartment & $69(16.0)$ & $13(13.4)$ & & & $0(0)$ & & \\
\hline Lack of social support & $9(2.2)$ & $3(3.1)$ & 0.37 & .54 & $0(0)$ & 0.23 & .58 \\
\hline Psychological distress & & & 41.86 & $<.001$ & & 8.97 & .002 \\
\hline No $(\mathrm{GHQ}<3)$ & $224(52.2)$ & $17(17.3)$ & & & $1(7.7)$ & & \\
\hline Yes (GHQ $\geq 3)$ & $205(47.8)$ & $81(82.7)$ & & & $12(92.3)$ & & \\
\hline
\end{tabular}

Note. GHQ = General Health Questionnaire.

${ }^{*}$ Chi-square analyses; Fisher's test (small $n$ 's).

Table 2. Association between violence by different abusers and suicidal thoughts and suicide attempts $(N=540)$ : Chi-square analyses.

\begin{tabular}{|c|c|c|c|c|c|c|c|c|}
\hline & $\begin{array}{l}\text { Not report } \\
\text { suicidal } \\
\text { thoughts } 440 \\
(81.5 \%) \\
\end{array}$ & $\begin{array}{c}\begin{array}{c}\text { Suicidal } \\
\text { thoughts } \\
98(18.1 \%) \\
\end{array} \\
\end{array}$ & & & $\begin{array}{c}\text { Not report } \\
\text { suicide attempts } \\
525(97.2 \%) \\
\end{array}$ & $\begin{array}{c}\text { Suicide } \\
\text { attempts } \\
13(2.4 \%) \\
\end{array}$ & & \\
\hline Variable & $n(\%)$ & $n(\%)$ & $x^{2}$ & $p$-value* & $n(\%)$ & $n(\%)$ & $x^{2}$ & $p$-value* \\
\hline Lifetime violence & $121(27.5)$ & $62(63.2)$ & 8.38 & .005 & 177 (33.7) & $13(100)$ & 6.48 & .04 \\
\hline IPV & $80(18.2)$ & 32 (32.6) & 16.84 & $<.001$ & $113(21.5)$ & $7(53.8)$ & 5.55 & .01 \\
\hline Physical & $19(4.3)$ & $3(3.0)$ & 0.40 & .78 & $23(4.4)$ & $1(7.7)$ & 0.99 & .33 \\
\hline Sexual & $3(0.7)$ & $4(4.1)$ & 6.82 & .026 & $5(0.9)$ & $2(15.4)$ & 28.94 & .006 \\
\hline Psychological & $58(13.2)$ & $25(25.5)$ & 7.68 & .006 & $85(16.2)$ & $4(30.8)$ & 1.79 & .18 \\
\hline Non-IPV & $28(6.4)$ & $21(21.4)$ & 20.91 & $<.001$ & $44(8.4)$ & $4(30.8)$ & 18.09 & .001 \\
\hline Friend & $4(0.9)$ & $4(4.1)$ & 5.50 & .04 & $7(1.3)$ & $1(7.7)$ & 5.04 & .14 \\
\hline Classmate & $17(3.9)$ & $10(10.2)$ & 6.76 & .009 & $25(4.8)$ & $2(15.4)$ & 4.79 & .08 \\
\hline Unknown person & $7(1.6)$ & $7(7.1)$ & 9.74 & .002 & $12(2.3)$ & $1(7.7)$ & 12.16 & .02 \\
\hline Family & - & - & & & - & - & & \\
\hline Both (IPV and non-IPV) & $13(2.9)$ & $9(9.2)$ & 10.15 & .004 & $20(3.8)$ & $2(15.4)$ & 7.58 & .04 \\
\hline $\begin{array}{l}93(17.2 \%) \text { did not } \\
\text { answer the questions } \\
\text { related to violence }\end{array}$ & $79(14.6)$ & $14(2.6)$ & 0.67 & 0.41 & $91(16.8)$ & $2(0.4)$ & 0.06 & .68 \\
\hline
\end{tabular}

Note. Violence categories are mutually exclusive.

${ }^{*} X^{2}=$ Chi-square analyses; Fisher's test (small n's). 
Table 3. Effect of interpersonal violence on student's suicidal behavior: logistic regression models $(N=447)$.

\begin{tabular}{|c|c|c|c|c|c|c|c|c|}
\hline \multirow[b]{2}{*}{ Variable } & \multicolumn{4}{|c|}{ Suicidal thoughts } & \multicolumn{4}{|c|}{ Suicide attempts } \\
\hline & AOR (Cl 95\%) & $p$-value & $R^{2}$ & $\mathrm{~F}^{\mathrm{a}}$ & AOR (Cl 95\%) & $p$-value & $R^{2}$ & $\mathrm{~F}^{\mathrm{a}}$ \\
\hline Not abused & 1 & & & & 1 & & & \\
\hline Abused & $1.86[1.17,2.95]$ & .009 & 0.19 & & $2.81[1.31,9.90]$ & .03 & 0.21 & \\
\hline By partner (IPV) & $1.85[1.06,3.23]$ & .02 & 0.14 & 1 & $2.38[1.03,8.93]$ & .04 & 0.17 & 1 \\
\hline By nonpartner (non-IPV) & $4.17[2.11,8.24]$ & $<.001$ & 0.19 & $3.48^{*}$ & $8.14[2.15,20.8]$ & .002 & 0.28 & $3.34^{*}$ \\
\hline By both (IPV and non-IPV) & $3.42[1.30,8.95]$ & .01 & 0.19 & na & $7.24[1.04,15.2]$ & .04 & 0.31 & na \\
\hline
\end{tabular}

Note. Abuse categories are mutually exclusive. AOR = adjusted odds ratio (for age and psychological distress); $\mathrm{Cl}=\mathrm{confidence}$ interval; $R^{2}=$ Nagelkerke $R^{2}$; na = not applicable.

${ }^{a} F$ statistic (adjusted Wald $F$-test).

${ }^{*} p<.05$.

decided not to answer the violence questions: 14 (2.6\%) reported suicidal thoughts and two (0.4\%) suicide attempts. Violence by a current or former partner is higher $(39 ; 52 \%)$ than by a nonpartner (25; 33.4\%). Psychological IPV is more commonly reported (29 females, 38.6\%) than sexual IPV (6 females, $8 \%$ ) or physical IPV (4 females, 5.3\%). The 63.2\% of the students with suicidal thoughts have experienced incidents of violence; $32.6 \%$ inflicted by an intimate partner and $21.4 \%$ by a nonpartner; while all who reported suicide attempts experienced incidents of violence; $53.8 \%$ by a partner and $30.8 \%$ by a nonpartner. Most of nonpartner violence is committed by people close to women (classmates and friends), while assaults by an unknown person comprised a $7.1 \%$ of reported suicidal thoughts and $7.7 \%$ suicide attempts. Given that violence inflicted by a partner does not exclude violence by others than a partner, 11 (14.6\%) have been abused by both, partner and nonpartner. Physical IPV doesn't appear associated to suicidal thoughts nor to suicide attempts, whereas sexual IPV is associated to suicidal thoughts $(p=.026$, Fisher's test) and suicide attempts ( $p=.006$, Fisher's test), and psychological IPV to suicidal thoughts $(p=.006$, chi-squared test).

Table 3 shows the results of the adjusted regression analysis. After excluding those students who did not respond to the violence questions, the final sample for analysis included 447 students. The low number of some categories of violence has led us to group violence by others than a partner in a single category: nonpartner. Students who experienced any form of violence are more likely to report suicidal thoughts $(\mathrm{AOR}=1.86)$ and suicide attempts $(\mathrm{AOR}=2.81)$ than nonabused students. Even though the likelihood for suicidal thoughts and attempts are higher for women abused by nonpartner $(\mathrm{AOR}=4.17$; $\mathrm{AOR}=8.14$ ) than by a partner $(\mathrm{AOR}=1.85$; $\mathrm{AOR}=2.38)$. In addition, the magnitude of the effect is stronger if violence was inflicted by others than an intimate partner, either in students reporting suicidal thoughts or attempts. Despite the wide confidence intervals achieved, for those who experienced violence by both (partner and nonpartner), the likelihood was higher for attempts $(\mathrm{AOR}=7.24)$ than for ideations $(\mathrm{AOR}=3.42)$.

\section{Discussion}

At least one in five female university students reported suicidal behavior; $18.1 \%$ suicidal thoughts in the last month and $2.4 \%$ had attempted suicide in the past five years. Our estimates are higher than those found in the United States, where the $11.4 \%$ of university students have seriously considered attempting suicide and $1.7 \%$ had attempted suicide at least once (Barrios, Everett, Simon, \& Brener, 2000). Our results are even higher than those found in a Spanish study, where rates were of $3.67 \%$ for suicidal thoughts and $1.46 \%$ for suicide (Miret et al., 2014). How suicidal behavior has been defined and assessed, age distribution of the study population and cultural context could explain the differences between studies. Suicidal thoughts are more commonly reported among students ages 18-21, whereas those ages 22-25 tend to report more suicide attempts. Given that suicidal behavior-starting with suicidal ideas and thoughts, progressing to plans and then developing suicidal attempts (Runeson, Beskow, \& Waern, 1996) - and suicide 
attempts have a high rate of onset in the one and five year's intervals following exposure to IPV (Rees et al., 2014), those who reported suicide attempts may have had longer exposure to violence than younger females.

Overall our results confirm that all forms of violence against female university students are strongly associated to suicidal behavior. This finding is in line with a previous study that stated that intimate partner violence and nonpartner violence are the most consistent risk factor for women suicide attempts, even after adjusting for probable common mental health disorders (Devries et al., 2011). Although IPV has been found lower among university students than among undergraduate students (Forke, Myers, Catallozzi, \& Schwarz, 2008), university students with suicidal behavior reported higher incidents of violence committed by the partner than by others, especially in students who attempted suicide. The most common abuse committed by a nonpartner was by classmates, followed by a stranger, but neither of the students surveyed reported family abuse. The fact that university students often have less adversity in childhood and more educated parents than young women in general (Turner \& Butler, 2003) can help to understand why students in our sample did not report family violence.

The last estimation of lifetime violence against women worldwide reveals that one out of every three women will experience some form of physical or sexual abuse inflicted by an intimate partner or sexual violence by a nonpartner (Abrahams et al., 2014). Moreover, 33\% of European women have experienced physical or sexual violence since the age of 15 (Agency for Fundamental Rights (FRA), 2014). Despite psychological IPV is more prevalent than physical and sexual IPV (Coker, Smith, McKeown, \& King, 2000), most studies analyze only severe physical or sexual IPV, likely to be more visible than other forms of violence. The long-term enduring psychological abuse, even in the absence of a history of physical or sexual abuse, has been found to be associated with poor mental health (Lawrence, Yoon, Langer, \& Ro, 2009), without significant mental health differences between those that reported psychological IPV only and those who reported psychological plus physical or sexual IPV (Yoshihama, Horrocks, \& Kamano, 2009). We found that $25.5 \%$ of those who reported suicidal thoughts or suicide attempts and $30.8 \%$ suicide attempts behavior experienced also psychological violence by a past or current partner, with a much higher proportion than those who experienced physical violence (3.0\% suicidal thoughts and $7.7 \%$ suicide attempts). These data confirm than psychological abuse but not physical abuse, was associated with increased suicidal thoughts in women university students (Saewyc et al., 2009). Although sexual IPV is less frequent than psychological IPV, the strong association found between sexual violence and student's suicide attempts, suggests that sexual abuse is relatively more important in explaining suicide attempts than physical violence, as in the absence of sexual abuse, suicide attempts by women over lifetime fall to 28\% (Babbington et al., 2009).

Prior studies state that the magnitude of the relationship between IPV and adverse health's effects increases as the number of violence types increases (Margolin, Vickerman, Oliver, \& Gordis, 2010; Mcnutt, Carlson, Persaud, \& Postmus, 2002), but few analyze the impact of violence performed by different perpetrators on young women's health. We found that the effect on suicidal thoughts and suicide attempts is more pronounced in students abused by different perpetrators than for students who experienced abuse by only one perpetrator. Since cumulative experience of childhood abuse had a graded association with IPV victimization (Vézinaet et al., 2015), it is likely that $14.6 \%$ of students who experienced violence by both (IPV and non-IPV), have been abused during their childhood. In this sense, it is not possible to identify if the violence was during childhood and who was the aggressor if we don't specifically ask about violence during childhood. A recent study with a representative sample of young Spanish women found that the impact on health is similar, whether violence is exercised by an intimate partner or by others (Martín-Baena, Montero-Piñar, EscribàAgüir, \& Vives-Cases, 2015). In contrast our results show that the magnitude of the effect on suicidal behavior in university students is greater if violence is committed by others than by an intimate partner. The discrepancy between these two Spanish studies may be explained considering the sampling method used and how the outcomes are expressed. 
The transition from high school to university implies navigating through unfamiliar environments, away from families and peer network involvement, pressures for academic success frequently related to college financial burden costs on families, which leads students to endure more and new demands and responsibilities (Wilcox et al., 2010). Results show a considerable association between psychological distress and reports of suicide ideation (82.7\%) and attempts (92.3\%). Although psychological distress is commonly reported by university students, rates vary depending on social and cultural context, as well as on the analyses tool used (Stallman, 2010). Since Spanish university students often live in or near their parents' homes and tend to maintain peer network environments, a lower psychological distress of students was expected in comparison to other countries. In contrast, we found a high level of psychological distress compared with $25.7 \%$ of French university colleagues (Saïas et al., 2014). Reducing social and academic pressure on young adults enrolled in higher education institutions should be a priority for the academic authorities.

Despite an increase in the management of people with suicidal behavior over the past decade, incidence rates of suicidal conduct have remained largely unchanged (Nock et al., 2008). There is still insufficient evidence to support widespread implementation of any programs or policies for primary suicide prevention in university and other post-secondary educational settings (Harrods, Goss, Stallones, \& DiGuiseppi, 2014). Since anxiety and its disorders are risk factors for suicidal thoughts and behaviors ${ }^{52}$ and suicidal thoughts are common in young people ages 12-30 (Scott et al., 2012), training health providers should be trained to understand and underlay connection between violence and suicidal behavior. This would help to identify violence against young women and work against it, reducing psychological distress and suicidal behavior as an investment for the future.

\section{Limitations}

This study has the usual biases of self-reporting and certain data could be misclassified. Our inability to establish the different types of violence (physical, sexual, and psychological) experienced in each relationship setting requires cautious interpretation. The exclusion of those who did not respond to the violence questions may mismatch experiences and outcomes. Moreover, as we did not specifically ask about violence during childhood or adolescence, we may have obtained a conservative estimate of the lifetime violence among students. The small sample size for suicide attempts limited the possibility of analyzing the effect independently for each category of violence. Finally, as the sample was based on a convenience-selected approach, the extent to which these findings can be generalized to students of other university degrees is limited.

\section{Conclusions}

Despite all these methodological limitations, the present study shows the strong association between suicidal behavior and violence committed by two very different abusers in women university students, a topic that is of interest to researchers, health providers and academic authorities. As the relationship between suicidal behavior and the different forms and types of violence is poorly understood, future studies should consider young women enrolled in higher educational institutions to better understand the effect of different forms and types of violence on student's suicidal behavior. Ensuring that young women enjoy healthy relationships and freedom from violence, could help to prevent future depressions and suicide attempts.

\section{Acknowledgments}

Authors thank all the students who gave their time to complete the questionnaire and shared their experiences with us. We gratefully thank the teachers who gave their time to gather the information. Without the collaboration of both, this study would not have been possible. In memoriam of Isabel Montero Piñar, who left us recently. 


\section{Conflict of interest disclosure}

The authors have no conflicts of interest to report. The authors confirm that the research presented in this article met the ethical guidelines, including adherence to the legal requirements, of Spain and received approval from the Institutional Review Board of the University of Spain.

\section{Funding}

This manuscript is part of the project "Mental health of young people (18-30 years) suffering from interpersonal violence and risk of suicidal behavior," funded by the Health Department of the Regional Government of Valencia (Spain; SM23/2014); Health Department of the Regional Government of Valencia (Spain [SM23/2014].

\section{ORCID}

Marta Talavera (D) http://orcid.org/0000-0002-1250-0200

\section{References}

Abrahams, N., Devriers, K., Watts, C., Pallito, S., Petzold, M., Shamu, S., \& García-Moreno, C. (2014). Worldwide prevalence of non-partner sexual violence: A systematic review. Lancet, 383(9929), 1648-1654. doi:10.1016/S01406736(13)62243-6

Agency for Fundamental Rights (FRA). (2014). Violence against women: An EU-Wide survey. Main results. Vienna, Austria: European Union Agency for Fundamental Rights.

Babbington, P. E., Cooper, C., Minot, S., Brugha, T. S., Jenkins, R., Meltzer, H., Dennis, H. (2009). Suicide attempts, gender, and sexual abuse: Data from the 2000 British psychiatric morbidity survey. The American Journal of Psychiatry, 166, 1135-4062. doi:10.1176/appi.ajp.2009.09030310

Barrios, L. C., Everett, S. A., Simon, T. R., \& Brener, N. D. (2000). Suicide ideation among US college students: Associations with other injury risk behaviors. Journal of American College Health, 48(5), 229-233. doi:10.1080/ 07448480009599309

Beautrais, A. L. (2006). Women and suicidal behavior. Crisis, 27(4), 153-156. doi:10.1027/0227-5910.27.4.153

Callanan, V., \& Davis, M. (2012). Gender differences in suicide methods. Social Psychiatry Psychiatric Epidemio, 47(6), 857-869. doi:10.1007/s00127-011-0393-5

Cibis, A., Mergl, R., Bramesfeld, A., Althaus, D., Niklewski, G., Schmidtke, A., Hegerl, U. (2012). Preference of lethal methods is not the only cause for higher suicide rates in males. Journal of Affective Disorders, 136, 9-16. doi:10.1016/j.jad.2011.08.032

Coker, A. L., Smith, P. H., McKeown, R. E., \& King, M. J. (2000). Frequency and correlates of intimate partner violence by type: Physical, sexual, and psychological battering. American Journal of Public Health, 90, 533-559.

Devries, K., Watts, C., Yoshihama, M., Kiss, L., Schraiber, L. B., Deyessa, N. (2011). WHO Multi-Country Study Team. Violence against women is strongly associated with suicide attempts: Evidence from the WHO multi-country study on women's health and domestic violence against women. Social Sciences Medica, 73(1), 79-86. doi:10.1016/j. socscimed.2011.05.006

Eisenberg, D., Gollust, S. E., Golberstein, E., \& Hefner, J. L. (2007). Prevalence and correlates of depression, anxiety and suicidality among university students. The American Journal of Orthopsychiatry, 77, 534-542. doi:10.1037/00029432.77.4.534

Eskin, M., Sun, J. M., Abuidhail, J., Yoshimasu, K., Kujan, O., Janghorbani, M. (2016). Suicidal behavior and psychological distress in university students: A 12-nation study. Archives Suicide Researcher, 8, 1-20.

Espinoza-Gómez, F., Zepeda-Pamplona, V., Bautista-Hernández, V., Hernández-Suárez, C. M., Newton-Sánchez, O. A., \& Plasencia-García, G. R. (2010). Domestic violence and risk of suicidal behavior in university adolescents. Salud Pública De México, 52(3), 213-219. doi:10.1590/S0036-36342010000300005

Forke, C. M., Myers, R. K., Catallozzi, M., \& Schwarz, D. F. (2008). Relationship violence among female and male college under-graduate students. Archives of Pediatrics \& Adolescent Medicine, 162(7), 634-641. doi:10.1001/ archpedi.162.7.634

Harrods, C. S., Goss, C. W., Stallones, L., \& DiGuiseppi, C. (2014). Interventions for primary prevention of suicide in university and other post-secondary educational settings. Cochrane Database Systems Reviews, 29(10), CD009439. doi: $10.1002 / 14651858$

Hawton, K. (2000). Sex and suicide. Gender differences in suicidal behavior. Brit Journal Psychiatry, 177, 484-485. doi:10.1192/bjp.177.6.484

Hawton, K., Arensman, E., Wasserman, D., Hulten, A., Bille-Brahe, U., Bjerke, T., Crepet, P., Deisenhammer, E., Kerkhof, A., De Leo D, Michel, K., Ostamo, A., Philippe, A., Querejeta, I, Salander-Renberg, E., Schmidtke, A., 
Temesváry, B. (1998). Relation between attempted suicide and suicide rates among young people in Europe. Journal of Epidemiology and Community Health, 52, 191-194. doi:10.1136/jech.52.3.191

Kessler, R. C., \& Ustün, T. B. (2004). The World Mental Health (WMH) survey initiative version of the World Health Organization (WHO) Composite International Diagnostic Interview (CIDI). International Journal Methods Psychiatric Researcher, 13(2), 93-121. doi:10.1002/mpr.168

Krantz, G., \& García-Moreno, C. (2005). Violence againts women. Journal of Epidemiology and Community Health, 59 (10), 818-821. doi:10.1136/jech.2004.022756

Krug, E. G., Dahlberg, L. L., Mercy, J. A., Zwi, A. B., \& Lozano, R. (2002). World report on violence and health. Geneva, Switzerland: World Health Organization.

La Flair, L. N., Bradshaw, C. P., \& Campbell, J. C. (2011). Intimate partner violence/abuse and depressive symptoms among female health care workers: Longitudinal findings. Women Health Issues, 22, e53-e59. doi:10.1016/j. whi.2011.07.001

Lagdons, S., Armour, C., \& Tringer, M. (2014). Adult experience of mental health outcomes results of intimate violence victimization: A systematic review. Journal of Psychotraumatology, 12(5). doi:10.3402/ejpt.v5.24794 eCollection 2014.

Lawrence, E., Yoon, J., Langer, A., \& Ro, E. (2009). Is psychological aggression as detrimental as physical aggression? The independent effects of psychological aggression on depression and anxiety symptoms. Violence and Victims, 24, 20-35. doi:10.1891/0886-6708.24.1.12

Margolin, G., Vickerman, K. A., Oliver, P. H., \& Gordis, E. B. (2010). Violence exposure in multiple interpersonal domains: Cumulative and differential effects. The Journal of Adolescent Health, 47, 198-205. doi:10.1016/j. jadohealth.2010.01.020

Martín-Baena, D., Montero-Piñar, I., Escribà-Agüir, V., \& Vives-Cases, C. (2015). Violence against young women attending primary care services in Spain: Prevalence and health consequences. Family Practice, 32(4), 381-386.

Martín-Baena, D., Talavera, M., \& Montero, I. (2016). Interpersonal violence and health in female university students in Spain 2016. Journal of Nursing Scholarship, 48(6), 561-568. doi:10.1111/jnu.12239

McLaughlin, J., O’Carroll, R. E., \& O’Connor, R. C. (2012). Intimate partner violence and suicidality: A systematic review. Clinical Psychologist Reviews, 32(8), 677-689. doi:10.1016/j.cpr.2012.08.002

Mcnutt, L. A., Carlson, B. E., Persaud, M., \& Postmus, J. (2002). Cumulative abuse experiences, physical health and health behaviors. Annals of Epidemiology, 12, 123-130. doi:10.1016/S1047-2797(01)00243-5

Mergl, R., Koburger, N., Heinrichs, K., Székely, A., Tóth, M. D., Coyne, J., Quintão, S., Arensman, E., Coffey, C., Maxwell, M., Värnik, A., van Audenhove, C., McDaid, D., Sarchiapone, M., Schmidtke, A., Genz, A., Gusmão, R., Hegerl, U. (2015). What are reasons for the large gender differences in the lethality of suicidal acts? An epidemiological analysis in four European Countries. PLoSOne, 10(7), e0129062. doi:10.1371/journal.pone.0129062

Miret, M., Caballero, F. F., Huerta-Ramírez, R., Moneta, M. V., Olaya, B., Chatterji, S., Haro, JM., Ayuso-Mateos. J. L. (2014). Factors associated with suicidal ideation and attempts in Spain for different age groups. Prevalence before and after the onset of the economic crisis. Journal of Affective Disorders, 163, 1-9. doi:10.1016/j.jad.20142014

Montero, I., Escribá, V., Ruíz-Pérez, I., Vives-Cases, C., Martín-Baena, D., Talavera, M., \& Plazaola, J. (2011). Interpersonal violence and women's psychological well-being. Journal of Women's Health, 20(2), $295-301$. doi:10.1089/jwh.2010.2136

Nock, M. K., Borges, G., Bromet, E. J., Alonso, J., Angermeyer, M., Beautrais, A., Bruffaerts, R., Chiu, WT., de Girolamo, G., Gluzman, S., de Graaf, R., Gureje, O., Haro, JM., Huang, Y., Karam E, Kessler, RC., Lepine, JP., Levinson, D., Medina-Mora, ME., Ono, Y., Posada-Villa, J., Williams, D. (2008). Cross-national prevalence and risk factors for suicidal ideation, plans and attempts. The British Journal of Psychiatry, 192(2), 98-105. doi:10.1192/bjp. bp.107.040113

Patel, V., Ramasundarahettige, C., Vijayakumar, L., Thakur, J. S., Gajalakshmi, V., Gururaj, G., Suraweera, W., Jha, P. (2012). Million death study collaborators. Suicide mortality in India: A nationally representative survey. Lancet, 379 (9834), 2343-2351. doi:10.1016/S0140-6736(12)60606-0

Rees, S., Steel, Z., Creamer, M., Teesson, M., Bryant, R., McFarlane, A. C., Mills, KL., Slade, T., Carragher, N., O’Donnell, M., Forbes, D., Silove, D. (2014). Onset of common mental disorders and suicidal behavior following women's first exposure to gender based violence: A retrospective, population-based study. BMC Psychiatry, 14, 312 . doi:10.1186/s12888-014-0312-x

Ruiz-Perez, I., Plazaola-Castano, J., Álvarez-Kindelan, M., Palomo-Pinto, M., Arnalte-Barrera, M., Bonet-Pla, A., De Santiago-Hernando, ML., Herranz-Torrubiano, A., Garralón-Ruiz, LM., Gender Violence Study Group. (2006). Socio-demographic associations of physical, emotional, and sexual intimate partner violence in Spanish women. Annals of Epidemiology, 16, 357-363. doi:10.1016/j.annepidem.2005.03.007

Runeson, B. S., Beskow, J., \& Waern, M. (1996). The suicidal process in suicides among young people. Acta Psychiatric Scandinavian, 93, 35-42. doi:10.1111/j.1600-0447.1996.tb10616.x9

Saewyc, E. M., Brown, D., Plane, M. B., Mundt, M. P., Wiegel, J., \& Fleming, M. F. (2009). Gender differences in violence exposure among university students attending campus health clinics in the U.S. and Canada. The Journal of Adolescent Health, 45(6), 587-594. doi:10.1016/j.jadohealth.2009.03.024 
Saïas, T., Du Roscoät, E., Véron, L., Guignard, R., Richard, J. B., Legleye, S., Sauvade, F., Kovess, F., Beck, F. (2014). Psychological distress in French college students: Demographic, economic and social stressors. Results from the 2010. National Health barometer. BMC Public Health, 14, 256. doi:10.1186/1471-2458-14-256

Sánchez-López, M. P., \& Dresch, V. (2008). The 12-Item General Health Questionnaire (GHQ-12): Reliability, external validity and factor structure in the Spanish population. Psicothema, 20(4), 839-843.

Schrijvers, D. L., Bollen, J., \& Sabbe, B. G. (2012). The gender paradox in suicidal behavior and its impact on the suicidal process. Journal of Affective Disorders, 138(1-2), 19-26. doi:10.1016/j.jad.2011.03.050

Scott, E. M., Hermens, D. F., Naismith, S. L., White, D., Whitwell, B., Guastella, A. J., ... Hickie, I. B. (2012). Thoughts of death or suicidal ideation are common in young people aged 12 to 30 years presenting for mental health care. BMC Psychiatry, 12, 234. doi:10.1186/1471-244X-12-234

Spanish Observatory for Suicide. (2013). Mental Health Foundation for the prevention of mental disorders and suicide. Statistics. Retrieved from www.fsme.es/observatorio-del-suicidio/españa/

Stallman, H. M. (2010). Psychological distress in university students: A comparison with general population data. Australian Psychologist, 45, 249-257. doi:10.1080/00050067.2010.482109

Sutherland, C., Bybee, A., \& Sullivan, C. (1998). The long-term effects of battering on women's mental health. Womens Health, 4, 41-70.

Turner, H. A., \& Butler, M. J. (2003). Direct and indirect effects of childhood adversity on depressive symptoms in young adults. Journal of Youth and Adolescence, 32(2), 89-103. doi:10.1023/A:1021853600645

Värnik, P. (2012). Suicide in the world. International Journal of Environmental Research and Public Health, 9, 760-771. doi:10.3390/ijerph9030760

Vézinaet, J., Hebert, M., Poulin, F., Lavoie, F., Vitaro, F., \& Tremblay, R. E. (2015). History of family violence, childhood behavior problems, and adolescent high-risk behaviors as predictors of girls' repeated patterns of dating victimization in two developmental periods. Violence against Women, 21(4), 435-459. doi:10.1177/ 1077801215570481

Watts, C., Yoshihama, M., Kiss, L., Schraiber, L. B., Deyessa, N., Heise, L., Durand, J., Mbwambo, J., Jansen, H., Berhane, Y., Ellsberg, M., Garcia-Moreno, C.; WHO Multi-Country Study Team. dre (2011). WHO Multi-Country Study Team. Violence against women is strongly associated with suicide attempts: Evidence from the WHO multicountry study on women's health and domestic violence against women. Social Sciences Medica, 73(1), 79-86. doi:10.1016/j.socscimed.2011.05.00646

Webster-Rudmin, F., Ferrada-Noli, M., \& Skolbekken, J. A. (2003). Questions of culture, age and gender in the epidemiology of suicide. Scandinavian Journal of Psychology, 44, 373-381. doi:10.1111/1467-9450.00357

Wilcox, H. C., Arria, A. M., Caldeira, K. M., Vincent, K. B., Pinchevsky, G. M., \& O’Grady, K. E. (2010). Prevalence and predictors of persistent suicide ideation, plans, and attempts during college. Journal of Affective Disorders, 127, 287-294. doi:10.1016/j.jad.2010.04.017

Wunderlich, U., Bronisch, T., Wittchen, H. U., \& Carter, R. (2001). Gender differences in adolescents and young adults with suicidal behavior. Acta Psychiatrica Scandinavica, 104(5), 332-339. doi:10.1034/j.1600-0447.2001.00432.x

Yoshihama, M., Horrocks, J., \& Kamano, S. (2009). The role of emotional abuse in intimate partner violence and health among women in Yokohama, Japan. American Journal of Public Health, 99, 647-653. doi:10.2105/ AJPH.2007.118976 